\title{
GAME EDUKASI PEMBELAJARAN MATEMATIKA UNTUK ANAK SD KELAS 1 DAN 2 BERBASIS ANDROID
}

\author{
Qadhli Jafar Adrian'), Apriyanti ${ }^{2)}$ \\ 1,2 Jurusan Informatika, Fakultas Teknik dan Ilmu Komputer, Universitas Teknokrat Indonesia \\ Jl. Zainal Abidin Pagar Alam No.9-11, Labuhan Ratu, Kedaton, Kota Bandar Lampung, Lampung 35132 \\ Email: 'qadhliadrian@teknorat.ac.id, ${ }^{2}$ apriyanti618@gmail.com
}

\begin{abstract}
Abstrak
Pendidikan adalah ilmu pengetahuan, yang memiliki proses (ilmu) dari tiga unsur utama, yaitu hakikat objek, proses pencarian kebenaran dan kegunaan. Pelajaran matematika merupakan pelajaran yang dipelajari dari jenjang SD, SMP, SMA sampai jenjang perguruan tinggi. Karakteristik matematika yang abstrak dan sistematis menjadi salah satu alasan sulitnya siswa mempelajari matematika. Meskipun demikian kenyataannya yang terjadi di sekolah menunjukan bahwa siswa tidak menyukai matematika karena di anggap sebagai bidang studi yang paling sulit di antara bidang studi yang lainnya Salah satu upaya membantu belajar siswa dengan menyerap pelajaran ke dalam bentuk game edukasi. Game Edukasi adalah game digital yang dirancang untuk pengayaan pendidikan (mendukung Pengajaran dan pembelajaran). Hasil dalam penelitian ini diketahui bahwa : 1) Hasil data pengujian kuesioner siswa, bahwa aplikasi game yang dibangun termasuk ke dalam kategori "Sangat Baik" dengan Hasil rata-rata yang diperoleh adalah 96\%. 2) Hasil data pengujian kuesioner guru, bahwa aplikasi game yang dibangun termasuk ke dalam kategori "Sangat Baik" dengan Hasil rata-rata yang diperoleh adalah 90\%. 3) Hasil data pengujian kompatibilitas pada perangkat smartphone dapat disimpulkan bahwa semua fungsi pada aplikasi Game Edukasi Pembelajaran Matematika Untuk Anak Sekolah SD Kelas 1 dan 2 Berbasis Android dapat dijalankan dengan baik.
\end{abstract}

Kata Kunci: game edukasi, matematika.

\section{Pendahuluan}

Pendidikan adalah ilmu pengetahuan, yang memiliki proses ( ilmu ) dari tiga unsur utama, yaitu hakikat objek, proses pencarian kebenaran dan kegunaan [1]. Salah satu masalah dalam pendidikan di Indonesia adalah lemahnya proses pembelajaran [2].

Pelajaran matematika merupakan pelajaran yang dipelajari dari jenjang SD, SMP, SMA sampai jenjang perguruan tinggi. Selain itu matematika sangat membantu dan di butuhkan pada bidang studi atau ilmuilmu yang lain. Pelajaran matematika di sekolah merupakan pelajaran dengan sarana berfikir yang jelas, kritis, kreatif, sistematis dan logis [3]. Karakteristik matematika yang abstrak dan sistematis menjadi salah satu alasan sulitnya siswa mempelajari matematika. Meskipun demikian kenyataannya yang terjadi di sekolah menunjukan bahwa siswa yang tidak menyukai matematika karena di anggap sebagai bidang studi yang paling sulit di antara bidung studi yang lainnya [4].

Berdasarkan latar belakang di atas, maka menjadi pertimbangan bagi penulis untuk membuat game edukasi pembelajaran matematika untuk anak sekolah sd kelas 1 dan 2 berbasis android, upaya ini dilakukan dengan menyerap pelajaran ke dalam bentuk game edukasi untuk mempermudah dalam mempelajarinya dengan harapan pemain dapat memahami tentang pelajaran matematika, namun dengan cara yang lebih menarik dan menyenangkan dibandingkan harus membaca suatu buku dengan memanfaatkan smartphone.

\section{Metode}

Model pengembangan rekayasa perangkat lunak multimedia yang digunakan adalah Model Luther (Multimedia Development Life Cycle) yaitu Model model yang dikembangkan melalui enam tahap seperti ditunjukkan pada Gambar 1 [9].

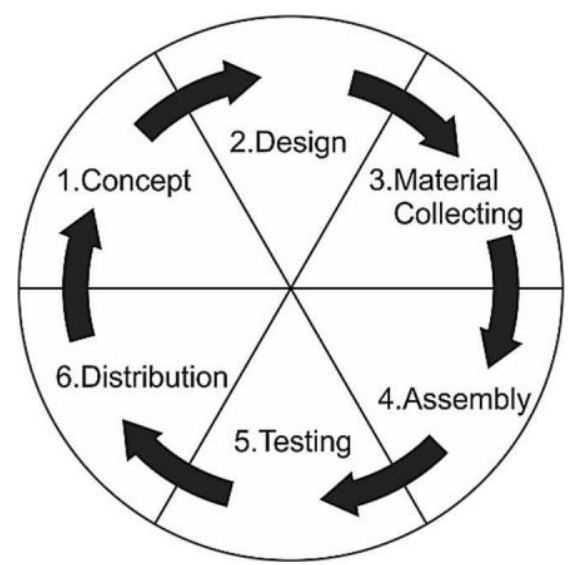

Gambar 1. Tahapan Pengembangan Multimedia

\subsection{Concept}

Tahap untuk menentukan tujuan dan siapa pengguna program (identifikasi audiens). Tujuan dan pengguna akhir program berpengaruh pada aplikasi game multimedia sebagai pencerminan dari pembelajaran yang ada.

\subsection{Design}

Tahap pembuatan spesifikasi mengenai arsitektur program, gaya, tampilan, dan kebutuhan material atau bahan untuk program. Spesifikasi dibuat serinci mungkin sehingga pada tahap berikutnya, yaitu material collecting dan assembly tidak terjadi pengulangan.Tahap 
perancangan yang dibuat meliputi storyboard, Unified Modelling Language (UML) diagram, Use Case Diagram, Activity Diagram, Sequence Diagram, Diagram alur sistem dan perancangan desain tampilan layar (Screen layouts).

\subsection{Material Collecting}

Tahap pengumpulan bahan yang sesuai dengan kebutuhan yang dikerjakan. Bahan-bahan tersebut, antara lain gambar clip art, foto, animasi, dan lain-lain yang dapat diperoleh secara gratis atau dengan mendesain sendiri sesuai dengan rancangannya.

\subsection{Assembly}

Tahap pembuatan semua objek atau bahan multimedia pembuatan aplikasi ini didasarkan pada tahap design, seperti storyboard, bagan alir, dan/atau struktur navigasi. Tahapan ini dibuat berbasis android.

\subsection{Testing dan distribution, atau implementasi}

Tahapan ini aplikasi di ujicobakan ke anak sekolah dasar negeri 2 labuhan dalam, bandar lampung. Dalam tahapan ini diagikan kuesioner. Kemudian aplikasi dibagikan.

\section{Hasil dan Pembahasan}

Pada bagian ini sistem telah digunakan oleh pengguna, tujuan implementasi adalah untuk menerapkan perancangan yang telah dilakukan terhadap sistem sehingga user dapat memberi masukan demi berkembangnya sistem yang telah dibangun. Setelah melakukan implementasi, maka anak dilanjutkan dengan pengujian sistem pada Game Edukasi Pembelajaran Matematika Untuk Anak Sekolah SD Kelas 1 dan 2 Berbasis Android.

\section{Implementasi Tampilan Menu Utama}

Pada rancangan ini terdapat tiga menu utama yaitu Pilih Permainan, Bantuan dan keluar. Menu pilih permainan digunakan untuk memilih game apa yang ingin di mainkan. Menu bantuan berisi tata cara bermain. Menu keluar digunakan untuk keluar dari game. Implementasi tampilan menu utama dapat dilihat pada Gambar 2.

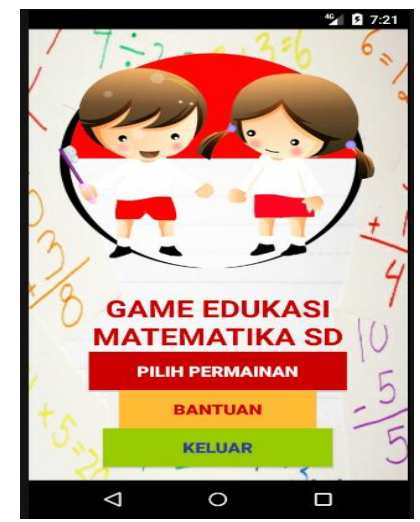

Gambar 2. Implementasi Tampilan Menu Utama

\section{Implementasi Tampilan Bantuan}

Pada menu bantuan ini berisi tata cara bermain. Tujuan dari menu ini adalah agar pemain dapat memahami permainan. Implementasi tampilan bantuan dapat dilihat pada Gambar 3.

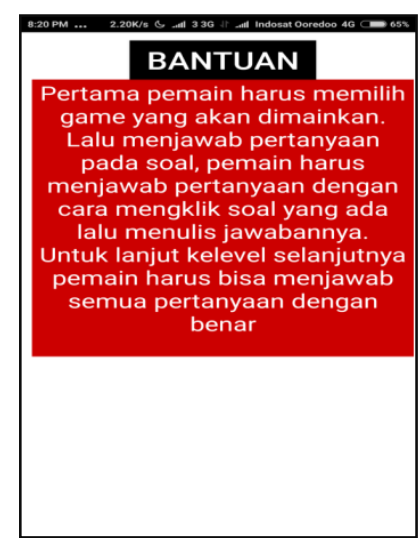

Gambar 3. Implementasi Tampilan Bantuan

\section{Implementasi Tampilan Kategori Permainan}

Di dalam menu ini terdapat empat pilihan kategori bermain yaitu penjumlahan, pengurangan, perkalian dan pembagian pemain bermain dengan materi-materi yang disediakan secara random. Implementasi tampilan kategori permainan dapat dilihat pada Gambar 4.

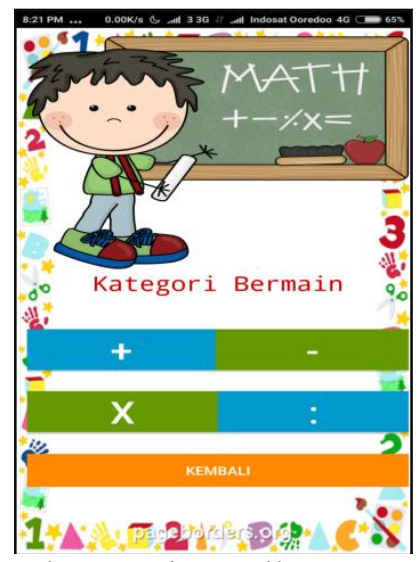

Gambar 4. Implementasi Tampilan Kategori Permainan

\section{Implementasi Tampilan Permainan}

Pada tampilan permainan ini pemain akan diberi pertanyaan berdasarkan materi-materi yang disediakan secara random. Untuk menjawab satu pertanyaan dengan benar pemain diberikan waktu 110 detik. Pemain disediakan 5 level dimana setiap level diberi 10 pertanyaan Jika ingin lanjut ke level selanjutnya pemain harus mendapatkan nilai 100 (dapat menjawab semua pertanyaan). Jika pemain menjawab pertanyaan ada yang salah 1 atau lebih, maka pemain harus mengulang bermain sampai nilai 100 agar dapat melanjutkan level selanjutnya. Implementasi tampilan permainan dapat dilihat pada Gambar 5. 


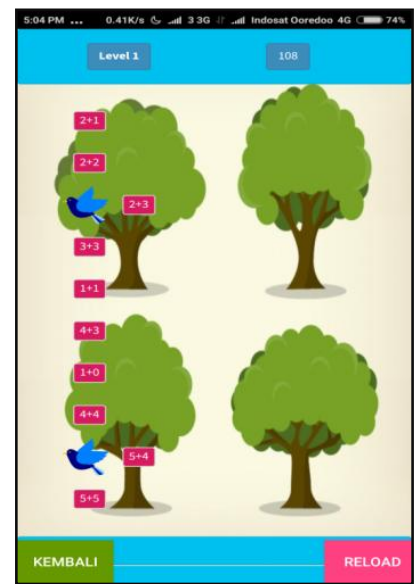

Gambar 5. Implementasi Tampilan Permainan

\section{Implementasi Tampilan Lengkap}

Tampilan Lengkap ini berisi nilai akhir dari hasil jawaban pemain dalam menjawab soal pertanyaan, gambar bintang bisa didapat dari jika pemain mendapat nilai 10 sampai 60 maka dapat satu bintang, jika nilai 70 maka dapat dua bintang, jika nilai 80 maka dapat tiga bintang, jika nilai 90 maka dapat empat bintang dan jika nilai 100 maka dapat lima bintang. Implementasi tampilan lengkap dapat dilihat pada Gambar 6 .

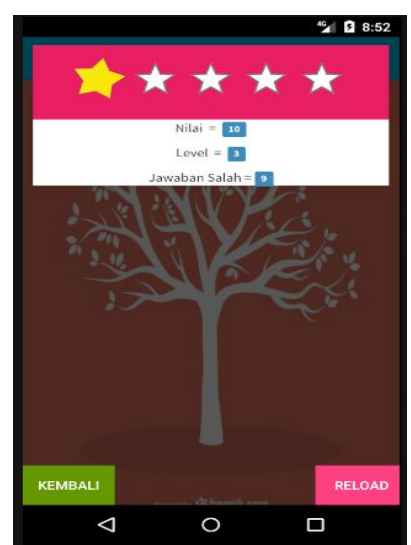

Gambar 6. Implementasi Tampilan Lengkap

\section{Implementasi Menu Akhir}

Tampilan ini akan muncul jika pemain dapat menyelesaikan semua game sampai level 5. Tampilan menu akhir dapat dilihat pada Gambar 7.

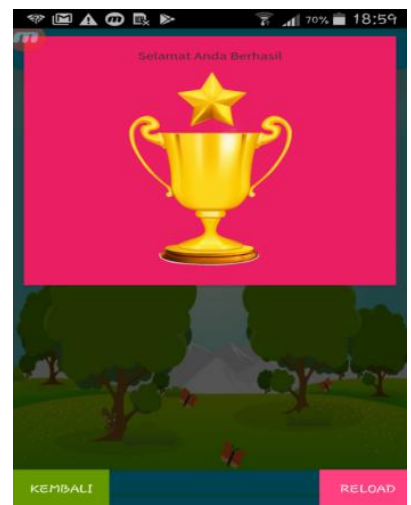

Gambar 7. Implementasi Menu Akhir

\section{Implementasi Menu Pesan Keluar}

Tampilan implementasi menu pesan keluar dapat dilihat pada Gambar 8.

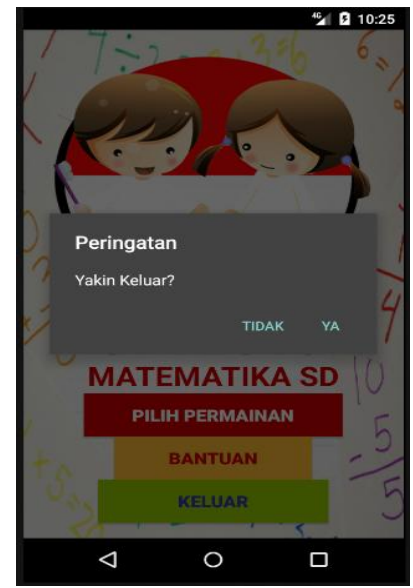

Gambar 8. Implementasi Menu Pesan Keluar

\section{Pengujian Game}

Pengujian pada game dibagi menjadi dua yaitu pengujian kuesioner dan pengujian kompatibilitas aplikasi pada perangkat smartphone. Pengujian kuesioner terhadap game edukasi pembelajaran matematikan untuk anak sekolah sd kelas 1 dan 2 berbasis android dilakukan di SD Negeri 2 Labuhan Dalam, Bandar Lampung. Untuk siswa kelas 1 dan 2 dengan jumlah masing-masing kelas 25 siswa, sehingga total siswa berjumlah 50 siswa.

\section{Pengujian dengan kuesioner}

Kuesioner siswa diberikan pada kelas 1 dengan jumlah 25 siswa, hasil pengisian dari kuesioner dari 7 kriteria penilaian pada 25 lembar kuesioner yang diberikan pada siswa ditunjukkan pada Tabel 1 . Kuesioner berikutnya diberikan pada kelas 2 dengan jumlah 25 siswa, hasil pengisian dari kuesioner dari 7 kriteria penilaian pada 25 lembar kuesioner yang diberikan pada siswa ditunjukkan pada Tabel 2.

Tabel 1. Hasil Pengisian Kuesioner pada Kelas 1

\begin{tabular}{cccccc}
\hline \multirow{2}{*}{ Kelas 1 } & \multicolumn{5}{c}{ Kategori } \\
\cline { 2 - 6 } & SS & S & C & TS & STS \\
\hline Responden & 150 & 22 & 3 & 0 & 0 \\
\hline
\end{tabular}

Tabel 2. Hasil Pengisian Kuesioner pada Kelas 2

\begin{tabular}{cccccc}
\hline \multirow{2}{*}{ Kelas 2 } & \multicolumn{5}{c}{ Kategori } \\
\cline { 2 - 6 } & SS & S & C & TS & STS \\
\hline Responden & 145 & 25 & 5 & 0 & 0 \\
\hline
\end{tabular}

Keterangan:
SS : Sangat Setuju
$\mathrm{S}$ : Setuju
C : Cukup
TS : Tidak Setuju
STS: Sangat Tidak Setuju

Perhitungan persentase akurasi:

Skor1 $=(150 \times 5)+(22 \times 4)+(3 \times 3)+(0 \times 2)+(0 \times 1)$

Skor1 $=(750)+(88)+(9)$

Skor $1=847$ 
Skor2 $=(145 \times 5)+(25 \times 4)+(5 \times 3)+(0 \times 2)+(0 \times 1)$ Skor $2=(725)+(100)+(15)$

Skor $2=840$

$\mathrm{Xi}=($ Skor 1$)+($ Skor2 $)$

$\mathrm{Xi}=(847)+(840)$

$\mathrm{Xi}=1.687$

$\mathrm{n}=50$

$\mathrm{N}=$ nilai bobot tertinggi $\times$ jumlah kriteria

$\mathrm{N}=5 \times 7$

$\mathrm{N}=35$

$$
\begin{gathered}
\mathrm{P}=\frac{\mathrm{Xi}}{\mathrm{n} \times \mathrm{N}} \times 100 \% \\
\mathrm{P}=\frac{1.687}{50 \times 35} \times 100 \% \\
\mathrm{P}=\frac{1.687}{1.750} \times 100 \% \\
\mathrm{P}=0,96 \times 100 \% \\
\mathrm{P}=96 \%
\end{gathered}
$$

Dari hasil data pengujian kuesioner siswa, bahwa aplikasi game yang dibangun termasuk ke dalam kategori "Sangat Baik" dengan Hasil rata-rata yang diperoleh adalah 96\%. Hasil analisis pengujian dan pengisian kuesioner yang dilakukan terhadap siswa, total skor kategori tertinggi pada kuesioner yang dibagikan ketiga kelas adalah 295 dan total skor untuk kategori terendah adalah 8. Kemudahan dan minat atau ketertarikan pada game oleh masing-masing siswa menjadi faktor utama tinggi rendahnya dalam menentukan penilaian terhadap game tersebut.

\section{Pengujian kompatibilitas pada Smartphone}

Pengujian kompatibilitas aplikasi pada smartphone terhadap Game Edukasi Tebak Gambar Keanekaragaman Budaya Indonesia Berbasis Android terdiri atas pengujian kompatibilitas versi sistem operasi, resolusi layar dan densitas layar, user interface, layout pilih kategori permainan, layout pada permainan, dan layout menu bantuan. Pengujian telah dilakukan pada smartphone Samsung Galaxy Grand 2 Duos (Android versi 4.4 Kitkat), Xiaomi Redmi Note 2 (Android versi 5.0 Lollipop).

Berdasarkan hasil pengujian kompatibilitas dengan melakukan instalasi pada smartphone android berbeda, dengan versi Operating System yang berbeda yaitu Kitkat dan Lollipop diperoleh hasil bahwa semua fungsi dapat dijalankan dengan baik pada versi Operating System Android Kitkat dan Lollipop. Sehingga dapat disimpulkan Game Edukasi Pembelajaran Matematika
Untuk Anak Sekolah SD Kelas 1 dan 2 Berbasis Android telah memenuhi aspek kompatibilitas.

\section{Kesimpulan}

Aplikasi Game Edukasi Pembelajaran Matematika Berbasis Android yang dibuat sebagai sarana media pembelajaran yang menarik dan menyenangkan dalam belajar matematika telah berhasil dikembangkan. berdasarkan hasil pengujian kuesioner siswa, bahwa aplikasi game yang dibangun termasuk ke dalam kategori "Sangat Baik" dengan hasil rata-rata yang diperoleh adalah $96 \%$. Sedangkan hasil data pengujian kompatibilitas pada perangkat smartphone diperoleh bahwa semua fungsi pada aplikasi Game Edukasi Pembelajaran Matematika Untuk Anak Sekolah SD Kelas 1 dan 2 Berbasis Android dapat dijalankan dengan baik dan telah memenuhi aspek kompatibilitas.

Adapun saran dalam penelitian ini yaitu, aplikasi ini dapat dikembangkan dengan menambahkan fiturfitur tambahan agar game lebih menarik. Selain itu, juga dapat menambahkan jenis game edukasi lainnya.

\section{Daftar Pustaka}

[1] Salim, Agus, 2007, Research \& Development, Jakarta: Rajawali Pers.

[2] Sanjaya Winna, 2007, Strategi Pembelajaran, Berorientasi Standar Proses Pendidikan. Jakarta: Penerbit Kencana Prenada Media Group.

[3] Lestari, Ika, 2003, Pengembangan Bahan Ajar Berbasis Kompetensi, Padang: Akademia.

[4] Puspawati GAK, 2009, Kajian Aktivitas Proliferasi Limfosit Dan Kapasitas Antioksidan Sorgum dan Jewawut Pada Tikus Sprague Dawley [tesis], Bogor: Program Pascasarjana Institut Perttanian Bogor.

[5] Z. R. Fahrul, 2010, Mahir Membuat Game Dalam $1 \mathrm{Jam}$, Yogyakarta.

[6] Oskar Morgenstern, John von Neumann, 1953, Theory of Games and Economic Behavior.

[7] Azwar, S, 2011, Sikap dan Perilaku Dalam: Sikap Manusia, Teori danPengukurannya, 2nd ed, Yogyakarta: Pustaka Pelajar.

[8] Darcey, L., Conder, S., 2013, Learning Android Application Programming for the Kindle Fire, Addision-Wesley, USA.

[9] Simarmata, Janner. 2010. Rekayasa Perangkat Lunak, ANDI, Yogyakarta. 